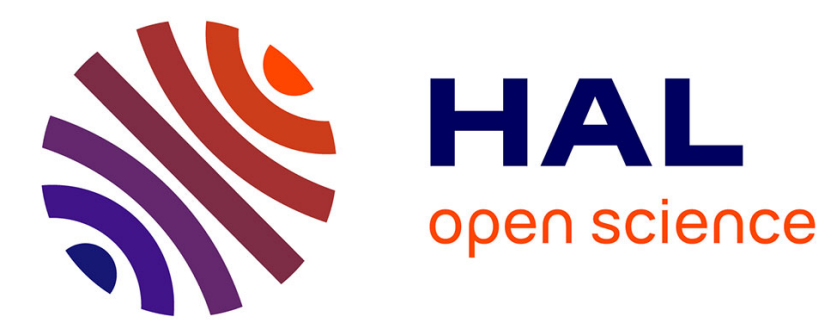

\title{
U.V. photoemission from sulphur saturated (100) and (110) nickel surfaces
}

\author{
R.C. Cinti, T.T.A. Nguyen
}

\section{To cite this version:}

R.C. Cinti, T.T.A. Nguyen. U.V. photoemission from sulphur saturated (100) and (110) nickel surfaces. Journal de Physique Lettres, 1977, 38 (1), pp.29-31. 10.1051/jphyslet:0197700380102900 . jpa-00231315

\section{HAL Id: jpa-00231315 https://hal.science/jpa-00231315}

Submitted on 1 Jan 1977

HAL is a multi-disciplinary open access archive for the deposit and dissemination of scientific research documents, whether they are published or not. The documents may come from teaching and research institutions in France or abroad, or from public or private research centers.
L'archive ouverte pluridisciplinaire HAL, est destinée au dépôt et à la diffusion de documents scientifiques de niveau recherche, publiés ou non, émanant des établissements d'enseignement et de recherche français ou étrangers, des laboratoires publics ou privés. 
Classification

Physics Abstracts

8.322

\title{
U.V. PHOTOEMISSION FROM SULPHUR SATURATED (100) AND (110) NICKEL SURFACES
}

\author{
R. C. CINTI and T. T. A. NGUYEN \\ Groupe des Transitions de Phases, C.N.R.S., B.P. 166, 38042 Grenoble Cedex, France
}

(Reçu le 27 septembre 1976, accepté le 8 novembre 1976)

\begin{abstract}
Résumé. - Les spectres de photoémission U.V. directionnelle obtenus sur les faces (100) et (110) du nickel, pures et saturées de soufre adsorbé, sont présentées. La gamme d'énergies d'excitation utilisée s'étend de 10,2 à $21,2 \mathrm{eV}$. Il est montré que les résultats obtenus sont complémentaires de ceux observés par Becker et Hagstrum par la technique I.N.S. et qu'ils sont en bon accord avec les prévisions théoriques de Kasowski.
\end{abstract}

\begin{abstract}
Directional U.V. photoemission spectra obtained on clean and sulphur saturated (100) and (110) nickel surfaces are presented for excitation energies lying in the range 10.2 to $21.2 \mathrm{eV}$. The results are shown to be complementary to the I.N.S. observations of Becker and Hagstrum and give an experimental support to the induced surface states predicted by Kasowski.
\end{abstract}

One of the most exciting aspects of U.V. photoemission is its application in chemisorption studies, from which one can get quality information on the electronic binding between substrate and adsorbed species. With the recent developments in theories of chemisorption [1] this may well lead to a fundamental understanding of this phenomenon. Interesting results have already been obtained on various systems in this way, especially on adsorbed phases of simple inorganic or organic gases on transition metal surfaces [2]. The present study is of this type.

In this letter, we report our first experimental results obtained on (100) and (110) Ni surfaces, both clean and saturated with adsorbed sulphur. The experimental work has been carried out on an ultra-high vacuum spectrometer described elsewhere [3].

The single crystals used in this experiment were cut along their respective crystallographic planes to within $0.5^{\circ}$. After good mechanical polishing and electropolishing, they were cleaned in situ by argonion bombardments and annealings until no trace of contamination, particularly by $\mathrm{S}$ and $\mathrm{C}$ was detectable by Auger analysis. During experiments on clean surfaces, contamination by $\mathrm{CO}$ was avoided by periodic thermal flashes to $450^{\circ} \mathrm{C}$ which desorbed $\mathrm{CO}$ without segregation of $\mathrm{S}$ from the bulk. Spectra were measured when the crystals were cooling in the temperature range between $450^{\circ} \mathrm{C}$ and $360^{\circ} \mathrm{C}$, where nickel is paramagnetic. Sulphurated surfaces were obtained either by dissociative $\mathrm{H}_{2} \mathrm{~S}$ adsorption [4] or by segregation of the chalcogen from the bulk when crystals were heated to $850^{\circ} \mathrm{C}$. No difference was observed in the results obtained with these two methods. Sulphuration was extended in order to have a saturation concentration on surfaces detected by a constant ratio between the $152 \mathrm{~V}$ and $61 \mathrm{~V}$ Auger peaks for $\mathrm{S}$ and $\mathrm{Ni}$, respectively. During measurements on these sulphurated surfaces, the temperature was maintained in the same range as for the clean ones. Several previous Leed and Auger studies [4, 5, $6,7]$ have shown, under these conditions, sulphur ordered overlayers having the $\mathrm{c}(2 \times 2)$ structure on . Ni (100) and the $\mathrm{p}(4 \times 1)$ structure on $\mathrm{Ni}(110)$.

Figure 1 shows 4 pairs of spectra obtained for $\hbar \omega=10.2,13.5,16.8$ and $21.2 \mathrm{eV}$ on a (100) surface, clean (dotted lines) and sulphurated (full lines). The bottom scale refers to the initial energy state of electrons before excitation relative to the Fermi level $E_{\mathrm{F}}$. No correction for the variation of the analyser resolution and transmission with energy was applied. In this set of experiments, the incident angle of the unpolarized light was about $48^{\circ}$ with respect to the surface normal and only electrons emitted in a $10^{\circ}$ cone centered around the surface normal were collected. For the same $\hbar \omega$, the total emission current was kept the same for both measured spectra.

A common feature observed for the four energies is the relative weakness of the principal structure originating from the $\mathrm{Ni}$ " $\mathrm{d}$ » band when $\mathrm{S}$ is present on the surface. An extra-peak occurs for $\hbar \omega=10.2 \mathrm{eV}$ at about $-1.75 \mathrm{eV}$ below $E_{\mathrm{F}}$. Well defined for this energy, it decreases for $\hbar \omega=13.5 \mathrm{eV}$ and is not 


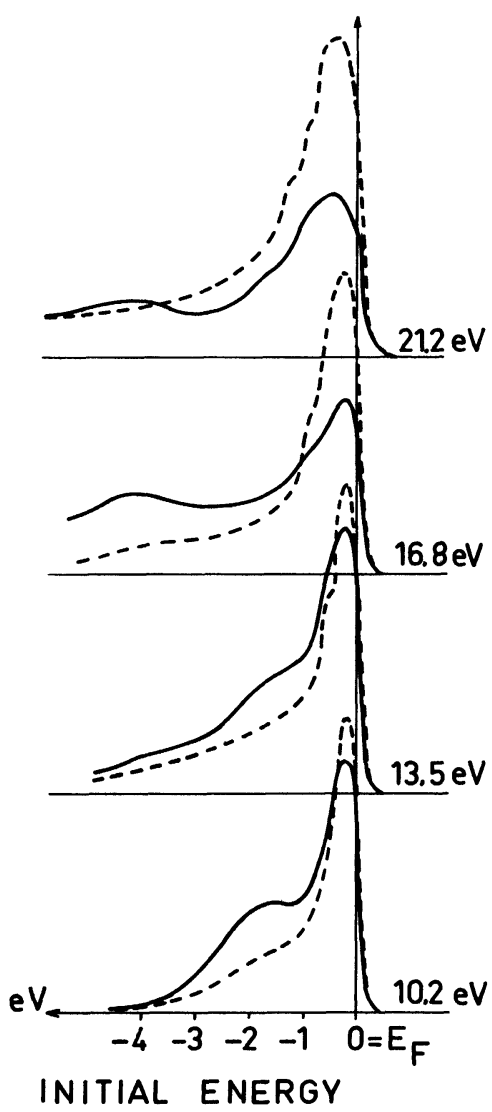

FIG. 1. - Energy distribution curves for a (100) Ni surface. Dotted lines : clean surface, full lines : surface saturated with adsorbed $\mathbf{S}$.

clearly apparent for the highest energies. Conversely for $\hbar \omega=16.8 \mathrm{eV}$ and $21.2 \mathrm{eV}$, there appears a new structure situated at $-4.25 \mathrm{eV}$ below $E_{\mathrm{F}}$ not detectable at lower $\hbar \omega$.

Experimentally these results should be compared with those of Hagstrum and Becker [7] obtained on the same system by ion-neutralization spectroscopy (I.N.S.). For the $c(2 \times 2)$ structure, probably present on our surface, they found also the diminution of the $\mathrm{Ni}$ structure and the extra-peak at $-4.25 \mathrm{eV}$ below $E_{\mathrm{F}}$. On the other hand, they did not observe the high energy level $-1.75 \mathrm{eV}$ below $E_{\mathrm{F}}$ occurring in our lowest excitation energy spectra, but found two low energy structures situated at $-8 \mathrm{eV}$ and $-9.5 \mathrm{eV}$ below $E_{\mathrm{F}}$ (this latter being perhaps ascribable to some contamination of the covered surface [7]).

Preliminary conclusions can be drawn at this step of discussion :

a) There are three (perhaps four if the $-9.5 \mathrm{eV}$ level was attributed to sulphur) sulphur-induced levels on (100) Ni surface.

b) Their ionization cross-sections vary greatly with the U.V. excitation energy.

c) They depend also on the means of excitation : ions or U.V. photons.

Theoretically, our results can be compared to the few calculations done on the chalcogen (100) $\mathrm{Ni}$ adsorption systems $[8,9]$. The most significant work is that of R. V. Kasowski [9] in which the electronic states of a paramagnetic (100) Ni film overlayed with ordered oxygen atoms have been calculated by a linear combination of muffin-tin orbital technique. Supposing that the chalcogen atoms are in fourfold sites above the hollow of the (100) surface, as suggested by Leed [10], his results are the following. The $\mathrm{O}_{2 p}$ states are split into two levels as expected by simple symmetry considerations : a doubly-degenerate nonbonding $p$ state and a deeper singly-degenerate state strongly hybridized with the $\mathrm{Ni}$. The non-bonding state is localized in the $\mathrm{O}$ overlayer because its interaction with the underlying $\mathrm{Ni}$ states is very weak. Conversely, the single degenerate state localizes some of the bulk extended states, by its strong interaction with the substrate, giving an induced surface state level situated in the s-d gap.

We think it reasonable to extend these results to the sulphur because of the similarity of the data obtained for these two elements adsorbed on (100) $\mathrm{Ni}$ by the self-consistent field $\mathrm{X} \alpha$ scattered wave method [8]. With this assumption, we can give a plausible interpretation of our experimental results :

a) The two structures observed at $-1.75 \mathrm{eV}$ and $-4.25 \mathrm{eV}$ below $E_{\mathrm{F}}$ are associated respectively with the induced-surface state and with the non-bonding $\mathrm{S}_{3 \mathrm{p}}$ state.

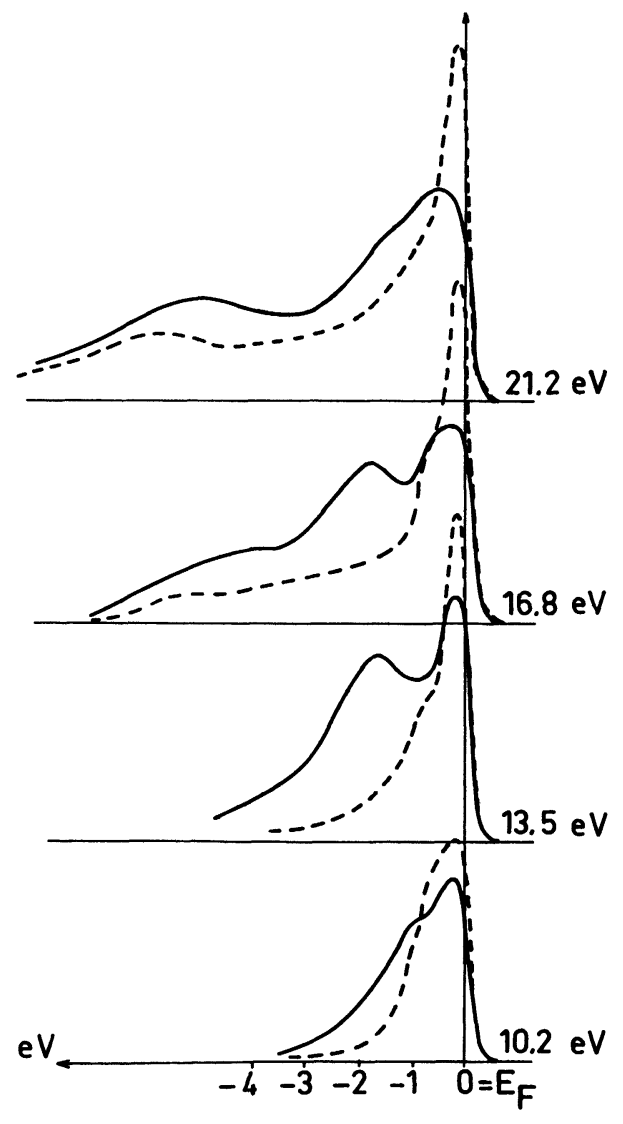

INITIAL ENERGY

FIG. 2. - Energy distribution curves for a (110) Ni surface. Dotted lines : clean surface, full lines : surface saturated with adsorbed $\mathbf{S}$. 
b) The deeper bonding state, not observed in our UPS measurements, is visible by I.N.S. technique at $-8 \mathrm{eV}$. (In this framework the deepest level appearing in the I.N.S. spectrum at $-9.5 \mathrm{eV}$ must be ascribed to contamination as discussed by the authors).

This interpretation gives a coherent explanation for all the extra-structures found both by U.P.S. and I.N.S.. Moreover it avoids the geometrically improbable bridge configuration proposed by Hagstrum and Becker [7] for adatoms on the surface and confirms the pyramidal configuration expected from Leed studies.

The parallel results obtained in the same experimental conditions on the (110) surface, clean and saturated with adsorbed sulphur, are shown in figure 2 . As for the (100) surface, adsorbed chalcogen decreases the $\mathrm{Ni}$ « $\mathrm{d}$ » band structure just below $E_{\mathrm{F}}$ principally towards the high excitation energies and two extrastructures appear. The first one, situated at $-1.9 \mathrm{eV}$ below $E_{\mathrm{F}}$, has an intensity maximum for $\hbar \omega=13.5 \mathrm{eV}$ and $16.8 \mathrm{eV}$, the second one grows at about $-5 \mathrm{eV}$ below $E_{\mathrm{F}}$ for $\hbar \omega=16.8 \mathrm{eV}$ and $21.2 \mathrm{eV}$. Comparing our results to the I.N.S. ones [6], we have to make the same remarks as before. One peak $(-5 \mathrm{eV})$ is observed by the two techniques with good agreement in energy position. Our high level structure $(-1.9 \mathrm{eV})$ is not seen by I.N.S., and the deep I.N.S. level $(-10 \mathrm{eV})$ is absent on our spectra.

Sulphur adsorption on a (110) $\mathrm{Ni}$ surface is more complex than on a (100) surface and has not yet been studied theoretically. We can however discuss the curious similarity between these two systems experimentally observed. It is remarkable that the extrastructures occurring in each case have the same behaviour with the variation of the excitation energy and are positioned in very similar energy levels. These facts suggest a close relationship between the sulphur adsorption phenomena on the (100) and (110) $\mathrm{Ni}$ surfaces already predicted by others $[4,5]$.

In summary, we have made UPS measurements on (100) and (110) Ni surfaces, clean and saturated with sulphur. The results are in agreement with and complementary to the I.N.S. measurements $[6,7]$ for the same systems. For the (100) surface, our results can be fully interpreted by taking into account inducedsurface states predicted by the Kasowski calculations. Experiments with collection angles different from the surface normal are currently being undertaken in order to examine the angular profiles of photoelectrons and to compare them with recent theoretical works $[11,12]$.

\section{References}

[1] Lyo, S. K. and Gomer, R., in Interactions on metal surfaces, edited by R. Gomer (Springer-Verlag Berlin Heidelberg, New York) 1975, p. 41.

[2] See for example : Demuth, J. E. and Eastìan, D. E., Phys. Rev. B 13 (1975) 1523.

Demuth, J. E. and Eastman, D. E., Solid State Commun. 18 (1976) 1497.

Eastman, D. E. and Demuth, J. E., Japan J. Appl. Phys. Supp. 2, part 2 (1974) 827.

[3] Cinti, R. C., Al Khoury, E., Chakraverty, B. K. and Christensen, N. E., Phys. Rev. B (1976), to be published.

[4] Perdereau, M. and Oudar, J., Surf. Sci. 20 (1970) 80.
[5] Demuth, J. E. and Rhodin, T. N., Surf. Sci. 45 (1974) 249.

[6] Becker, G. E. and Hagstrum, H. D., Surf. Sci. 30 (1972) 505.

[7] Hagstrum, H. D. and Becker, G. E., J. Chem. Phys. 54 (1971) 1015

[8] NiEmCZyK, S. J., J. Vac. Sci. Technol. 12 (1975) 246.

[9] Kasowski, R. V., Phys. Rev. Lett. 33 (1974) 1147.

[10] Demuth, J. E., Jepsen, D. W. and Marcus, P. M., Phys. Rev. Lett. 31 (1973) 540.

[11] Gadzuk, J. W., Phys. Rev. B 10 (1974) 5030.

[12] Tong, S. Y. and Van Hove, M. A., Solid State Commun. 19 (1976) 543 